\title{
Combined hypoxia inducible factor-1 $\alpha$ and homogeneous endothelial progenitor cell therapy attenuates shunt flow-induced pulmonary arterial hypertension in rabbits
}

Guangqing Cao, PhD, ${ }^{a}$ Chuanzhen Liu, PhD, ${ }^{a}$ Zhaojie Wan, MD, ${ }^{b}$ Kai Liu, $\mathrm{PhD},{ }^{a}$ Hourong Sun, PhD, Xiangfei Sun, MD, ${ }^{a}$ Mengmeng Tang, MD, ${ }^{a}$ Weidong Bing, $\mathrm{MD},{ }^{a}$ Shuming $\mathrm{Wu}, \mathrm{PhD},{ }^{a}$

Xinyan Pang, $\mathrm{PhD},{ }^{\mathrm{a}}$ and Xiquan Zhang, $\mathrm{PhD}^{\mathrm{a}}$

\section{ABSTRACT}

Background: Hyperkinetic pulmonary arterial hypertension (PAH) is a common complication in congenital heart disease, and affects operations, indications, and prognoses for patients. Gene-based stem cell transplantation is an alternative treatment that can attenuate PAH.

Methods: Hyperkinetic PAH rabbit models were successfully established, using common carotid artery and jugular vein anastomosis. Endothelial progenitor cells (EPCs) were isolated from the bone marrow, cultured, and transfected with human hypoxia inducible factor- 1 alpha (hHIF- $1 \alpha$ ), using lentiviruses. Two weeks after the transfected EPCs were transplanted into the rabbits, catheterization was applied to collect hemodynamic data. The hypertrophy of the right ventricle and pulmonary vascular remodeling were evaluated by measuring the right ventricle hypertrophy index, the medial wall thickness, and the medial wall area. Western blot and immunohistochemistry analyses were used to detect the expression of hHIF- $1 \alpha$ in the pulmonary small arteries.

Results: Two weeks after transplantation, systolic pulmonary arterial pressure and mean pulmonary arterial pressure were both attenuated. The hypertrophy of the right ventricle, and pulmonary vascular remodeling were reversed. Expression of hHIF- $1 \alpha$ in the hHIF- $1 \alpha$-transfected EPCs that had been transplanted was high, and the number of pulmonary small arteries had increased. In addition, combined HIF- $1 \alpha$ and homogeneous EPC therapy was more effective at attenuating PAH and increasing the density of pulmonary small arteries, compared with EPC transplantation alone.

Conclusions: Both the therapy with HIF- $1 \alpha$-transfected EPCs, and EPC transplantation, attenuated shunt flow-induced PAH, by means of an angiogenic effect. The former therapeutic method was more effective. (J Thorac Cardiovasc Surg 2015;150:621-32)

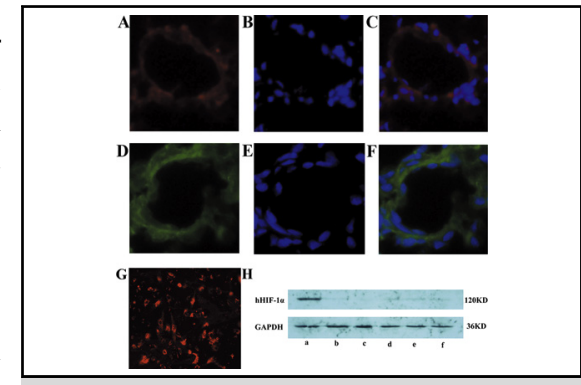

Endothelial progenitor cells transfected with hHIF-1 $\alpha$ formed the new vessels, and hHIF- $1 \alpha$ was expressed in the lung.

\section{Central Message}

Therapy using HIF-1 $\alpha$-transfected endothelial progenitor cells attenuates shunt flow-induced pulmonary arterial hypertension, by means of an angiogenic effect.

\section{Perspective}

A hyperkinetic PAH model was successfully established using common carotid artery and jugular vein anastomosis in rabbits. Transplantation of hHIF-1-transfected EPCs attenuated this shunt flow-induced PAH by means of an angiogenic effect. Our study provides further evidence to support regenerative cell-based gene strategies for the treatment of patients who have severe $\mathrm{PAH}$ and congenital heart disease.

See Editorial Commentary page 632

\footnotetext{
From ${ }^{\text {a }}$ The Key Laboratory of Cardiovascular Remodeling and Function Research, Division of Medicine, Department of Cardiovascular Surgery, Chinese Ministry of Education and Chinese Ministry of Health, Qilu Hospital of Shandong University, Jinan, Shandong, People's Republic of China; and 'Department of Geriatric Medicine, Qilu Hospital of Shandong University, Jinan, Shandong, People's Republic of China.

This work was supported by the Shandong Provincial Natural Science Foundation of China (People's Republic of China) (no. ZR2011HM025).

Received for publication Jan 26, 2015; revisions received April 24, 2015; accepted for publication May 9, 2015; available ahead of print June 11, 2015.

Address for reprints: Xinyan Pang, PhD, and Xiquan Zhang, PhD, Department of Cardiovascular Surgery, Qilu Hospital of Shandong University, Jinan 250012,

Shandong, People's Republic of China (E-mail: xinyanpang001@126.com or zhangxq0511@163.com).

$0022-5223 / \$ 36.00$

Copyright (C) 2015 by The American Association for Thoracic Surgery

http://dx.doi.org/10.1016/j.jtcvs.2015.05.035
}

Pulmonary arterial hypertension (PAH) is a progressive disease characterized by vascular cell proliferation, obliteration of small pulmonary arteries, and an increased resistance in pulmonary circulation. ${ }^{1}$ Hyperkinetic PAH developed in patients who have congenital heart disease is a significant contributor to morbidity and mortality, especially in those with Eisenmenger syndrome. ${ }^{2,3}$ In PAH, the pulmonary vasculature is exposed to high pressure; this increased flow causes pathologic changes that result in endothelial dysfunction and ultimately cause occlusive remodeling of the pulmonary arterioles. ${ }^{4}$ Increased right ventricular afterload induced by PAH leads to heart failure and death. 


$$
\begin{aligned}
& \text { Abbreviations and Acronyms } \\
& \mathrm{EPC}=\text { endothelial progenitor cell } \\
& \text { HGF = hepatocyte growth factor } \\
& \text { HIF-1 = hypoxia inducible factor-1 } \\
& \text { hHIF-1 = human hypoxia inducible factor-1 } \\
& \text { PAH = pulmonary arterial hypertension } \\
& \text { VEGF }=\text { vascular endothelial growth factor }
\end{aligned}
$$

Great improvements have been made in the treatment of $\mathrm{PAH}$, such as use of nitrous oxide inhalation, prostacyclin, and other oral drugs. ${ }^{6,7}$ However, the long-term outcome remains unsatisfactory because of the occlusive remodeling of the pulmonary arterioles and the decreased size of the pulmonary vascular bed. ${ }^{8}$ Therapeutic angiogenesis has been considered 1 of the most promising recent treatment strategies in fields such as acute myocardial infarction and limb ischemia. ${ }^{9,10}$

Transplantation of various types of cells has been suggested as a potentially effective angiogenic treatment for $\mathrm{PAH}$. These cell types include bone marrow mesenchymal stem cells,${ }^{11}$ adipose-derived stromal cells, ${ }^{12}$ and endothelial progenitor cells (EPCs). ${ }^{13,14}$ This last type is mainly derived from and identified in bone marrow, peripheral blood, and umbilical cord. EPCs have proliferative potential and can differentiate into mature endothelial cells. When PAH occurs, EPCs enter the peripheral blood and migrate to areas of endothelial damage, to replace dysfunctional endothelium. ${ }^{15}$ In addition, they can induce angiogenesis and increase the size of the pulmonary vascular bed, which can attenuate PAH.

Transplantation of EPCs can repair endothelial tissues and thus help prevent and treat PAH. However, a single transplantation of cells is not effective in all patients, because of the complicated mechanism of PAH. As a result, genebased therapy is used as an alternative to treat PAH. In prior studies, we have found that transfection of genes encoding endothelial nitric oxide synthase and hepatocyte growth factor (HGF) can alleviate hyperkinetic PAH in rabbit models. ${ }^{16,17}$ In addition, some studies ${ }^{18-21}$ have indicated that gene transfer of vascular endothelial growth factor (VEGF), prostacyclin synthase, and others ameliorate monocrotaline-induced PAH. Nonetheless, VEGF and HGF genes, which have therapeutic angiogenic effects on PAH, simultaneously have potential side effects, such as vascular permeability, interstitial edema, and inflammation. ${ }^{22}$

Hypoxia inducible factor-1 (HIF-1) has been described recently as a transcriptional factor associated with angiogenesis, and is expressed throughout the body. It plays a very general role in the increase in the size of the vascular bed, by signaling the existence of hypoxia. However, it has no side effects as do other angiogenic growth factors. ${ }^{23}$ Hypoxia inducible factor- 1 is a heterodimer consisting of
HIF-1 alpha (HIF- $1 \alpha$ ) and HIF-1 beta (HIF-1ß) subunits; its biological activity is determined by HIF- $1 \alpha$. Animal studies show that gene therapy using HIF- $1 \alpha$ can promote both angiogenesis and ischemic collateral vessel perfusion, and increase capillary density. ${ }^{24,25}$ These findings indicate that HIF-1 is superior to VEGF, HGF, and other angiogenic growth factors in promoting angiogenesis.

Based on this background, many researchers are looking for more-effective treatments for PAH. As an angiogenic therapeutic strategy, EPC transplantation combined with gene transfer has been used as a novel approach. Compared with EPC transplantation alone, PAH was ameliorated more significantly by transplantation of adrenomedullin DNA (deoxyribonucleic acid)-modified EPCs in monocrotaline rats. ${ }^{26}$ Moreover, treatment with VEGF-transfected EPCs, endothelial nitric oxide synthase-transfected EPCs, and prepro-calcitonin gene-related peptide-expressing EPCs effectively attenuated PAH and reversed pulmonary vascular remodeling. ${ }^{27-29}$ In addition, studies have demonstrated that all of these treatments were more effective than EPC treatment alone.

Therefore, we hypothesized that combined hHIF-1 and homogeneous EPC therapy may be a novel and reliable method to suppress progression of, and reverse, PAH in patients who have congenital heart disease. In this study, we established a hyperkinetic PAH rabbit model, using common carotid artery and jugular vein anastomosis. EPCs were isolated from bone marrow, cultured, and transfected by lentivirus-mediated hHIF- $1 \alpha$ in vitro. High hHIF- $1 \alpha-$ expressing EPCs were transplanted into the model rabbits to evaluate whether PAH was attenuated and/or pulmonary vascular remodeling reversed.

\section{METHODS}

\section{Animal Model Preparation}

One hundred male New Zealand white rabbits (age: 4 weeks; weight: $520 \pm 36 \mathrm{~g}$ ) were provided by the Laboratory Animal Center of Shandong University. The animals received humane care, and the experiments were performed in accordance with the guidelines of the Animal Care and Use Committee of Shandong University. The animals were housed individually at a constant ambient temperature and humidity, and on a 12-hour lightdark cycle.

After 7 days of acclimation, the rabbits were anesthetized with an intravenous injection of pentobarbital sodium $(30 \mathrm{mg} / \mathrm{kg}$ ). A $3-\mathrm{cm}$ incision was made in the middle of the neck, the right external jugular vein was exposed, and $1 \mathrm{mg} / \mathrm{kg}$ of heparin was injected intravenously. The right common carotid artery and the right internal jugular vein were carefully dissected. The right common carotid artery was clamped and ligated in the proximal and distal sites, respectively. The right common carotid artery was amputated just before the bifurcation. Under an operative microscope, a 2-mm hole was made in the right internal jugular vein, and an end-to-side anastomosis was made between the right common carotid artery and the right internal jugular vein using a polypropylene (Prolene; Ethicon, Inc, Somerville, NJ) 7-0 suture. Finally, the distal site of the jugular vein was ligated.

Once the artery clamp was released, pulsation and bulging of the proximal part of the jugular vein were observed ${ }^{30}$ (Figure 1). Penicillin was locally applied to prevent an infection, and aspirin $(10 \mathrm{mg} / \mathrm{kg} / \mathrm{day})$ was 


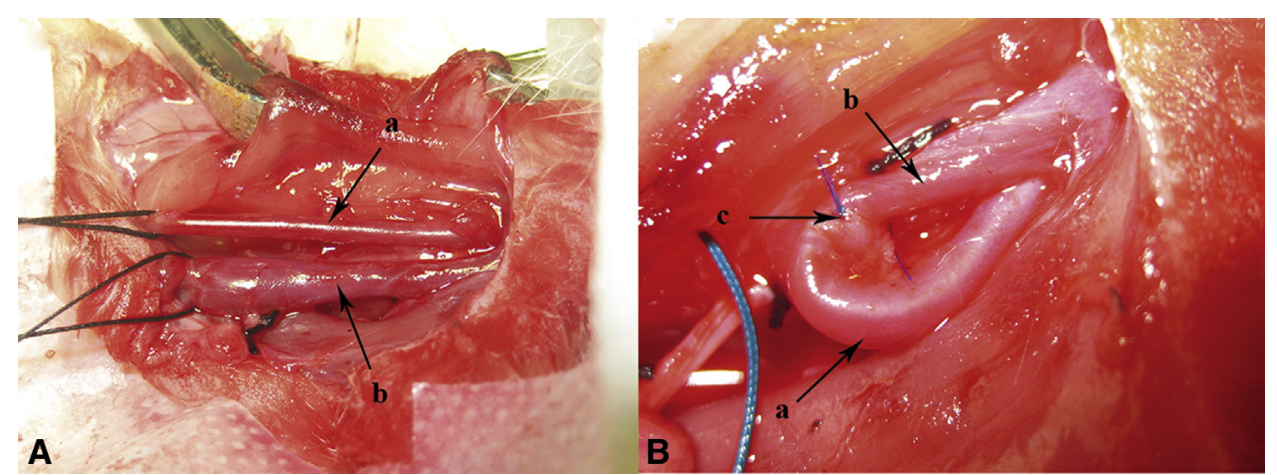

FIGURE 1. Common carotid artery and internal jugular vein anastomosis: (A) The right common carotid artery and right internal jugular vein were exposed; (B) right common carotid artery and right internal jugular vein anastomosis: (a) right common carotid artery; (b) the right internal jugular vein; $(c)$ anastomosis.

administrated as an anticoagulant until the end of the experiment, after the operation. A sham operation was performed by isolating the vessels from rabbits only.

\section{Isolation and Identification of EPCs}

According to a previously described method, ${ }^{31}$ mononuclear cells were isolated from the bone marrow of the long-limb bones of the rabbits using density gradient (Ficoll; Sigma, St Louis, Mo) centrifugation at $2000 \mathrm{~g}$ for 30 minutes. Bone-marrow mononuclear cells were washed twice with phosphate-buffered saline and pre-plated onto fibronectin-coated plates with complete EGM-2 medium (Lonza, Walkersville, Md) that included the following: $5 \%$ fetal bovine serum, VEGF, fibroblast growth factors-2, epidermal growth factor, insulin growth factor-1, ascorbic acid, hydrocortisone, heparin, and gentamicin/amphotericin-B. After 3 to 4 days of culture at $37^{\circ} \mathrm{C}$, with $5 \% \mathrm{CO}_{2}$, the nonadherent cells were discarded, and the culture medium was completely changed. All of the cells were further cultured for 2 weeks, and the culture medium was changed every 3 to 4 days.

An evaluation of EPCs was made by examining live cells for their ability to uptake fluorescently labeled acetylated low-density lipoprotein (Dilac-LDL, Invitrogen, Carlsbad, Calif). The cells were incubated with the Dil-ac-LDL $(10 \mathrm{mg} / \mathrm{mL})$ for 4 hours at $37^{\circ} \mathrm{C}$, fixed with $2 \%$ paraformaldehyde for 10 minutes, and incubated with $10 \mathrm{mg} / \mathrm{mL}$ of fluorescein isothiocyanate-Ulex europaeus agglutinin-1 (Sigma) at $37^{\circ} \mathrm{C}$ for 1 hour. After unbound dye was washed away, an inverted fluorescent microscope was used to observe the fluorescence.

To characterize the phenotype of the cells, they were detached with trypsin and washed with phosphate-buffered saline containing $0.2 \%$ fetal bovine serum. The cells were incubated for 30 minutes with monoclonal antibodies conjugated to fluorescein isothiocyanate or phycoerythrin. Appropriate isotype control combinations were performed. A fluorescence-activated cell sorter (BD FACSCalibur; BD Biosciences, San Jose, Calif) was used to determine CD34, CD133, and VEGF receptor-2 expression. Data acquisition and analysis were performed using BD CellQuest Pro software (BD Biosciences).

\section{Infection of EPCs with hHIF-1 $\alpha$ by Lentiviral Vector}

After approximately 2 weeks in culture, when the EPCs had high proliferation activity, they were infected with a lentivirus carrying 511BhHIF1 $\alpha$-green fluorescent protein (referred to here as hHIF-EPCs) and CD511B-1- green fluorescent protein (referred to here as control-EPCs; bought from WoRock Bio Tech Co, Shanghai, China), and cultured in a hypoxic incubator. Environmental hypoxic conditions ( $1 \%)$ were achieved in an airtight humidified chamber that was continuously inflated with a gas mixture containing $1 \% \quad \mathrm{O}_{2}, 5 \% \quad \mathrm{CO}_{2}$, and $94 \% \quad \mathrm{~N}_{2}$ at $37^{\circ} \mathrm{C}$. A microprocessor-based oxygen controller was used to monitor $\mathrm{O}_{2}$ concentration during incubation (Forma Scientific, Marietta, Ohio). Lentivirus medium was replaced with endothelial cell growth medium-2 after 24 hours. After that, the EPCs were cultured for 72 hours, and the green fluorescent signal emitted by the green fluorescent protein was detected using a fluorescence microscope.

\section{Experimental Groups}

Animals underwent an echocardiographic examination at 4, 8, and 12 weeks after the operation, to detect the patency of the anastomotic stoma and cardiac function. Catheterization was applied to collect the hemodynamic data after 12 weeks. Animals were anesthetized, followed by exposure of the left jugular vein. A $3 F$ polyethylene catheter was inserted into the vein and advanced first into the right ventricle, and from there into the main pulmonary artery under fluoroscopic guidance. The systemic pressure was monitored by the other catheter inserted into the left common carotid artery. The 2 catheters were both connected to a transducer, and the pulmonary arterial pressure and systemic pressure were recorded. The parameters were recorded 3 times per animal, and the average pressure was calculated. Successful model animals, as well as those with unobstructed anastomosis, were included in the analysis.

After collection of the hemodynamic data, the animal who underwent the sham operation, and those that were successful models, were separated into 6 groups, each with 10 animals: the sham group (underwent the sham operation); the blank group (had no treatment after PAH mode was established); the EPCs group (model rabbits who received $10^{7}$ EPCs in $5 \mathrm{~mL}$ of endothelial cell growth medium-2 transplanted through the right jugular vein); the hHIF-1-EPCs group (model rabbits who had10 hHIF- $1 \alpha$-transfected EPCs in $5 \mathrm{~mL}$ of endothelial cell growth medium-2 transplanted through the right jugular vein); the controlEPCs group (received an injection of $10^{7}$ mock-vehicle-transfected $\mathrm{EPCs}$ ); and the medium group (injection of $5 \mathrm{~mL}$ of only endothelial cell growth medium-2).

\section{Measurement of Hemodynamic Parameters}

Two weeks after transplantation of the lentivirus-hHIF- $1 \alpha$-infected EPCs, the rabbits were anesthetized with an intravenous injection of pentobarbital sodium $(30 \mathrm{mg} / \mathrm{kg})$. Catheterization was applied to collect the hemodynamic data, as previously described. The parameters were recorded 3 times per animal, and the average pressure was calculated.

\section{Preparation of Heart and Lung Tissues}

Once the hemodynamic data had been collected, the animals were killed with an overdose of pentobarbital sodium. The heart and lungs were rapidly 
dissected and weighed, and the heart tissue was separated into the right ventricle, and the left ventricle plus septum. The extent of right ventricle hypertrophy was evaluated by calculating the ratio of the weight of the right ventricle to that of the left ventricle plus septum. The left lung was fixed in phosphate-buffered $4 \%$ paraformaldehyde, and a part of the right upper lung lobe was removed and embedded in Tissue Freezing Medium (Tissue Tek; Sakura Finetek USA Inc, Torrance, Calif) to obtain a frozen slice to be used for immunohistochemistry to detect the engrafted cells. The residual lung tissues were subsequently flash frozen in liquid nitrogen and stored at $-80^{\circ} \mathrm{C}$ for western blot analysis.

\section{The Result of Injected EPCs and the Expression of hHIF-1 $\alpha$ in the Lung}

Endothelial progenitor cells from rabbits in the EPC treatment group were labeled with CM-DiL (Invitrogen), and successfully transfected EPCs in the hHIF-1-EPCs group expressed green fluorescent protein. They were assessed by fluorescent microscopy to determine the location of the EPCs in the lung.

The expression of hHIF- $1 \alpha$ in the lung was detected by western blot analysis. Total protein lysates were made by adding lysis buffer and phenylmethanesulfonyl fluoride (both from Beyotime, Shanghai, China), followed by centrifugation at $10,000 \mathrm{rpm}$ for 10 minutes $\left(4^{\circ} \mathrm{C}\right)$ to remove the tissue fragments of the sediments. Proteins were quantified using a bicinchoninic acid protein assay; protein samples were separated using sodium dodecyl sulfate polyacrylamide gel electrophoresis and transferred onto nitrocellulose membranes. The membrane was blocked with $5 \%$ fat-free milk for 2 hours, and incubated with mouse antihuman HIF- $1 \alpha$ antibody (BD Biosciences) overnight at $4^{\circ} \mathrm{C}$. The blots were incubated with horseradish peroxidase-conjugated secondary antibodies for 1 hour, at room temperature, with continuous shaking. An enhanced chemiluminescence kit (Millipore, Billerica, Mass) was used to detect the protein blots after washing, and the blots were exposed to radiograph film. The bands were quantified by FluorChem 9900 (Alpha Innotech, San Leandro, Calif), and glyceraldehyde-3-phosphate dehydrogenase was used as an internal reference.

\section{Morphology and Immunohistochemistry Analysis}

The left lung was fixed in phosphate-buffered $4 \%$ paraformaldehyde; after this step, it was dehydrated, embedded in paraffin, and cut into 5- $\mu \mathrm{m}$ slices. The slices were stained with hematoxylin-eosin and observed under an optical microscope. The external diameter and the internal diameter of 20 pulmonary arteries per lung section were measured by a blinded observer, as described elsewhere. ${ }^{32,33}$ The medial wall thickness and medial wall area were calculated as follows: $\%$ wall thickness $=[($ external diameter internal diameter)/external diameter $] \times 100$; and $\%$ wall area $=[$ (total area - internal area) / total area] $\times 100$.

For immunohistochemical analysis, the slices were treated with hydrogen peroxide and blocked with $5 \%$ bovine serum albumin. The slices were incubated with the primary antibodies (anti-factor VIII), overnight at $4^{\circ} \mathrm{C}$, and with horseradish peroxidase-coupled secondary antibody, for 30 minutes at $37^{\circ} \mathrm{C}$. Diaminobenzidine was used to visualize the color reaction; a brown color indicated a positive result. The number of factor VIII-positive arteries ( $>50 \mu \mathrm{m}$ in diameter) was counted under a microscope in 10 randomly selected fields per specimen. Arterial density was determined as the average number of factor VIII-positive arteries along the terminal bronchioles, per $\mathrm{mm}^{2}$. The pathologist reviewing the sections was blind to the experimental group.

\section{Statistical Analysis}

Data were expressed as mean \pm standard deviation (SD). One-way ANOVA with the post hoc Tukey HSD test was used for the statistical analysis among the treatment groups. All of the data in the study were evaluated using SPSS 17.0 (SPSS, Inc, Chicago, Ill).

\section{RESULTS \\ Characteristics of EPCs Derived From Bone Marrow}

Bone-marrow mononuclear cells were cultured in endothelial growth medium for 7 days, and exhibited the typical spindle-like shape and polygon that are typical of EPCs (Figure 2, A-C). Endothelial characteristics were assessed by the uptake of Dil-labeled, acetylated-low-density lipoprotein, and the binding of fluorescein isothiocyanateUlex europaeus agglutinin-1. Dual-positive adherent cells (Figure 2, D-F) indicated that they expressed the scavenger receptor for acetylated-low-density lipoprotein, and the ligand for Ulex europaeus agglutinin-1. Flow cytometry analysis showed that the cultured bone-marrow mononuclear cells were positive for CD34, CD133, and VEGF receptor-2, as reported previously (Figure 2, G). On the basis of these characteristics, the cells were considered to be bone-marrow EPCs. ${ }^{34,35}$

\section{Successful Transfection of hHIF-1 $\alpha$ Into EPCs}

Endothelial progenitor cells were transfected with lentiviral vectors carrying either 511B-hHIF $1 \alpha$-green fluorescent protein or CD511B-1-green fluorescent protein. After infection, $90 \%-95 \%$ of the cultured cells were green fluorescent protein positive (Figure 3, $A-D$ ).

\section{Therapy With Combined hHIF-1 and EPCs Attenuated PAH}

Hemodynamic analysis and right ventricle hypertrophy index of the 6 groups of rabbits are shown in Figure 4 and Table 1. Compared with the sham group, the systolic pulmonary arterial pressure, the mean pulmonary arterial pressure, and the ratio of the weight of the right ventricle to that of the left ventricle plus septum were significantly increased in the blank and medium groups $(P<.05)$. No significant difference was found between the blank group and the medium group. Compared with the blank group, these 3 measures were significantly lower in the EPC group and hHIF-1-EPC group $(P<.05)$. However, the hHIF-1-EPC group had a more obvious decrease in these 3 variables than the EPC group $(P<.05)$. No significant difference was found between the EPC group and the control-EPC group.

\section{Location of the hHIF-1 $\alpha$-Transfected EPCs and Expression of hHIF-1 $\alpha$ in the Lung}

No animal died or suffered from other disorders after the cell transplantation. Fluorescent microscopy was used to assess cells labeled with CM-DiL; the red fluorescence continued for several passages (Figure 5, G). The frozenslice analysis revealed that the engrafted EPCs in the lung were located in the surrounding capillary vessels and alveolar wall, 2 weeks after transplantation, and some EPCs had differentiated and formed a vascular 

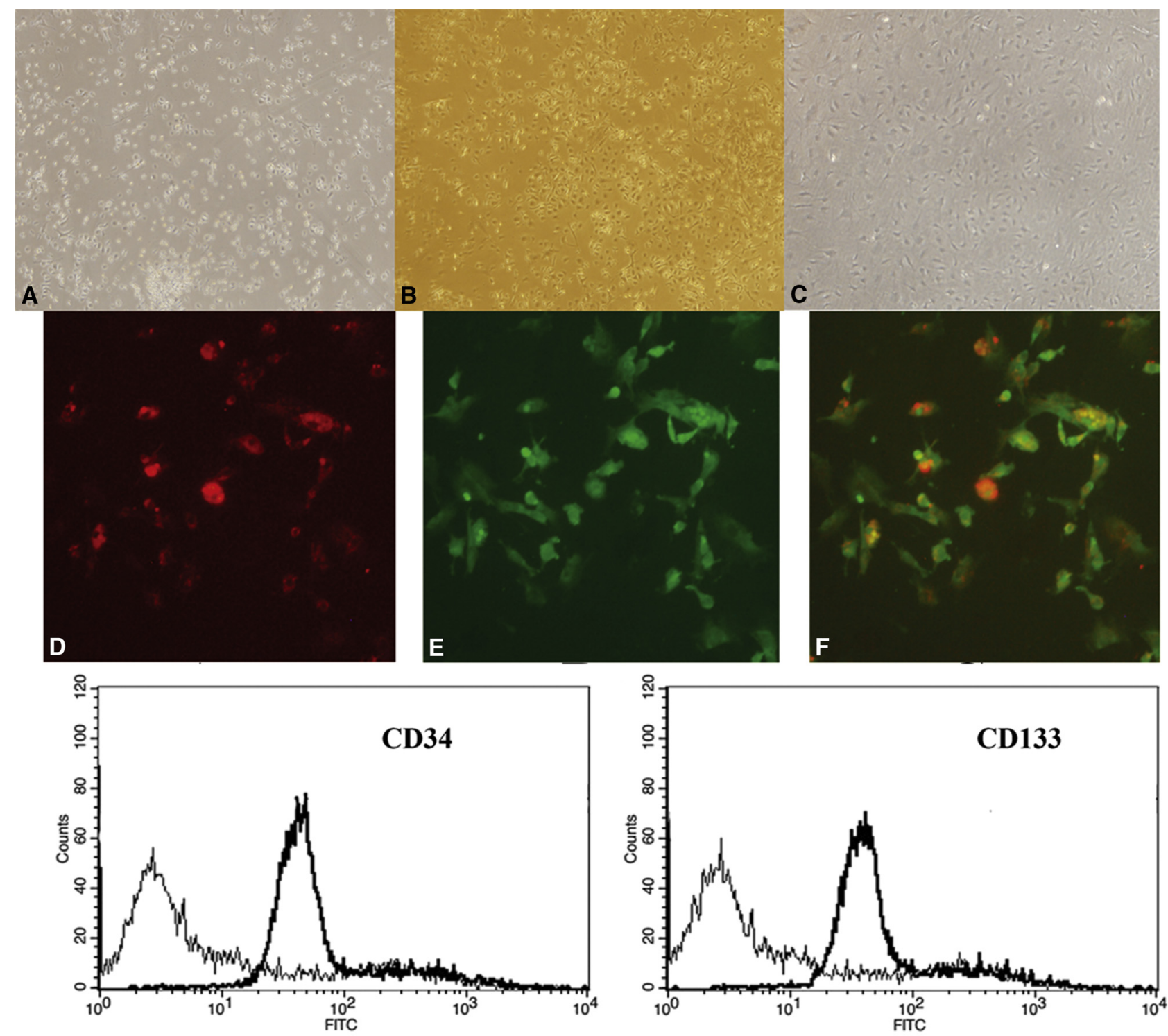

G

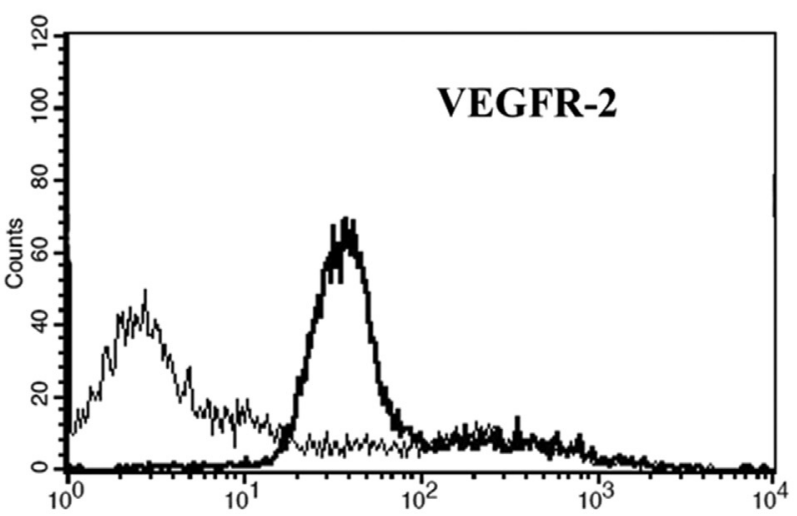

FIGURE 2. Characteristics and identification of EPCs derived from bone marrow: (A) BM-MNCs cultured for 24 hours were round in shape; (B) BMMNCs cultured for 7 days were in a typical colony, characterized by cells that are round and spindle-like in shape; (C) BM-MNCs cultured for 14 days were mainly spindle-like and polygonal in shape; (D) Cells with uptake of Dil-acetylated low-density lipoprotein fluoresced red; (E) Cells combined with FITC-Ulex europaeus agglutinin-1 fluoresced green; (F) Dual-positive adherent cells fluoresced in brown-orange; (G) BM-MNCs were positive for CD34, CD133, and vascular endothelial growth factor-2. 

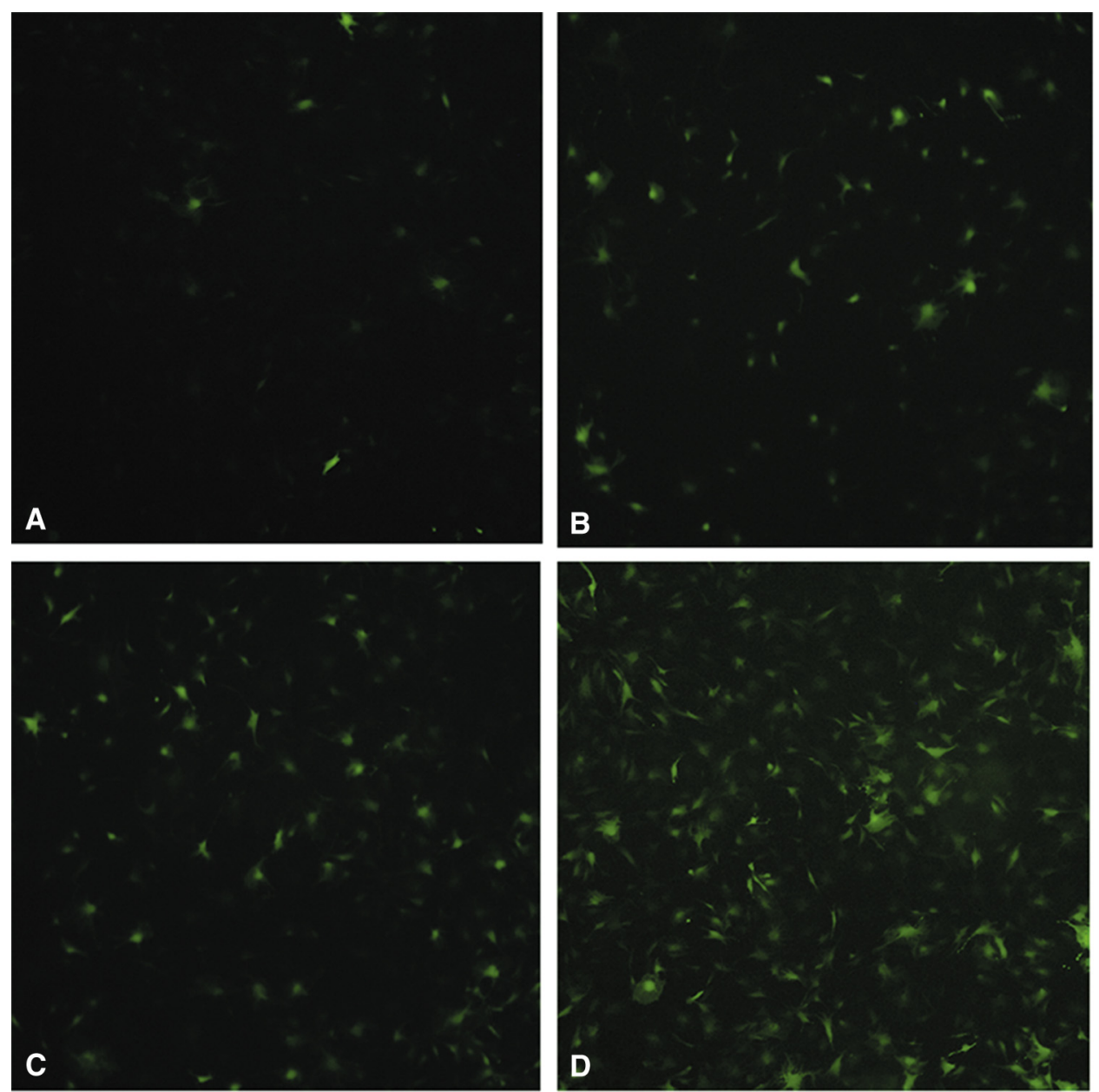

FIGURE 3. Expression of green fluorescent protein in hHIF- $1 \alpha$-transfected EPCs at: (A) 24 hours; (B) 48 hours; (C) 72 hours; and (D) 96 hours after transfection.

structure (Figure 5, $A-F$ ). Western blot analysis was used to measure hHIF- $1 \alpha$ protein expression; hHIF- $1 \alpha$-specific bands were detected in rabbits in the hHIF-1-EPCs group (Figure 5, H), and no band was observed in rabbits from the other groups.

\section{Combined hHIF-1 $\alpha$ and EPC Therapy Reversed Vascular Remodeling}

To determine the effect on vascular remodeling, we examined the wall thickness and wall area of the small pulmonary arteries and muscular arteries in our rabbits (Figure 6; Table 2). Compared with the sham group, the blank group and the medium group had a significant increase in the wall thickness and wall area of their pulmonary arteries $(P<.05)$. No significant difference was found between the blank group and the medium group. The EPC group and the hHIF-1-EPC group had significantly decreased wall thickness and wall area of the pulmonary arteries, compared with the blank group $(P<.05)$. However, the wall thickness and wall area decreased more obviously in the HIF-1-EPC group than in the EPC group $(P<.05)$. No significant difference was found between the EPC group and the control-EPC group.

\section{Angiogenic Effect of Combined hHIF-1 $\alpha$ and EPC Therapy}

To evaluate the effects of combined hHIF- $1 \alpha$ and EPC therapy on endothelial cells, we performed an immunohistochemical examination with antifactor VIII. Compared with the sham group, the blank group and medium group had a significant decrease in capillary density $(P<.05)$. A significant difference was found in capillary density between the EPC, hHIF-1-EPCs, and control-EPC groups, compared with the blank group $(P<.05)$. However, the hHIF-1-EPC group had a higher capillary density than the EPC group and the control-EPC group $(P<.05)$ (Figure 7), indicating that when PAH occurred, pulmonary arterioles were occluded. Transplantation of EPCs increased the number of small arteries, and HIF-1 improved the angiogenic effect. 

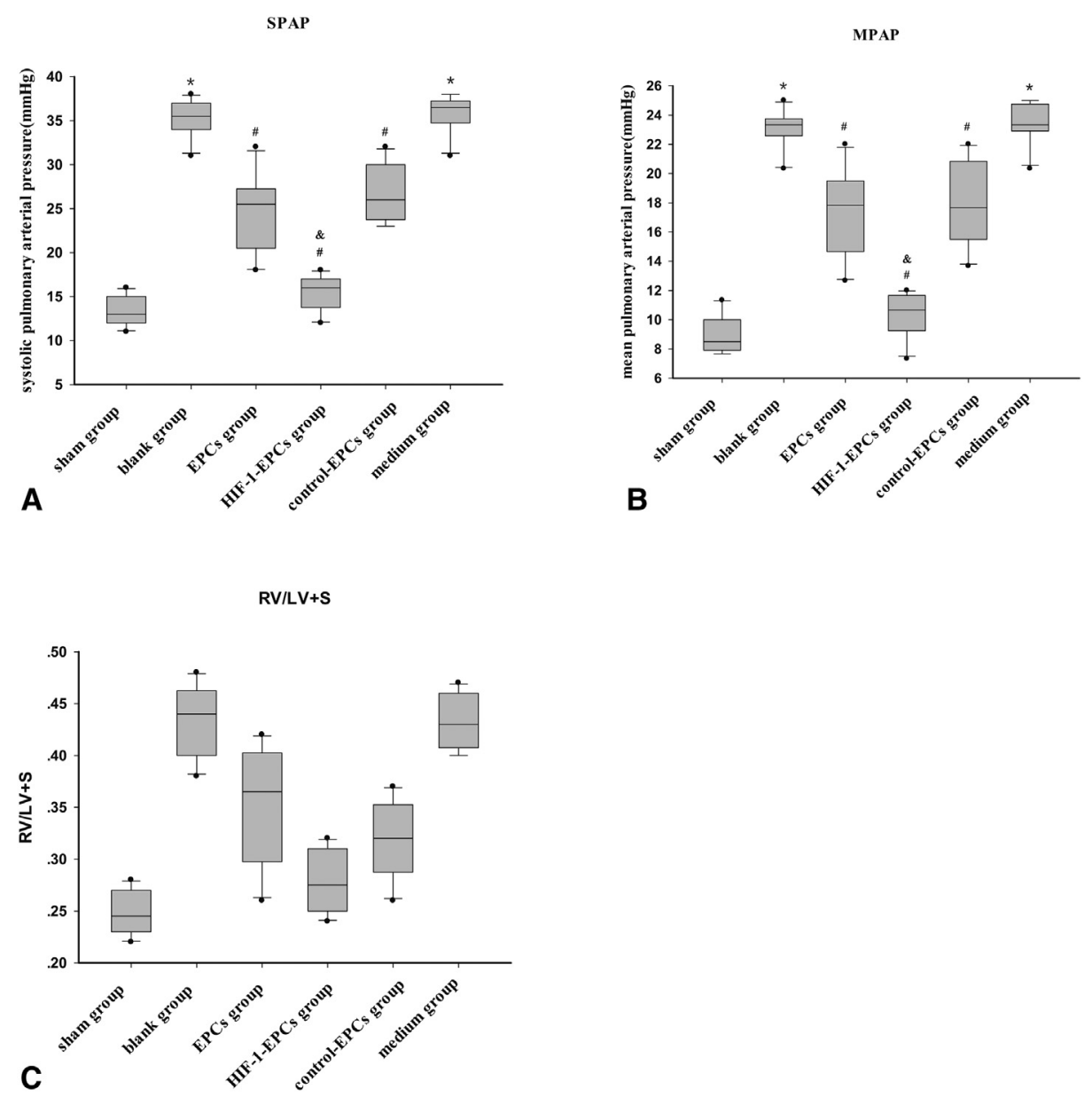

FIGURE 4. Hemodynamic analysis and right ventricle hypertrophy index of the 6 groups: (A) systolic pulmonary arterial pressure; (B) mean pulmonary arterial pressure; $(\mathrm{C})$ right ventricle hypertrophy index $(\mathrm{RV} / \mathrm{LV}+\mathrm{S})$. (Compared with the sham group, $* P<.05$; compared with the blank group, \#P<.05; compared with the EPC group, $\& P<.05$.) The median (horizontal line inside box) is shown as well as a box showing the interquartile ranges $(25$ th and 75 th percentile); individual outlier points beyond the 10th and 90 th percentiles are indicated. SPAP, Systolic pulmonary arterial pressure; MPAP, mean pulmonary arterial pressure; $E P C$, endothelial progenitor cell; $H I F$, hypoxia inducible factor; $R V$, right ventricle; $L V$, left ventricle; $S$, septum.

\section{DISCUSSION}

In the research reported in this article, we have established a hyperkinetic PAH model using common carotid artery and jugular vein anastomosis in rabbits, and this model represents the aberrant hemodynamic state in children who

TABLE 1. Hemodynamic data of the 6 groups

\begin{tabular}{lll}
\hline \multicolumn{1}{c}{ Group } & SPAP $(\mathbf{m m ~ H g})$ & MPAP $(\mathbf{m m ~ H g})$ \\
\hline Sham & $13.3 \pm 1.636$ & $8.97 \pm 1.356$ \\
Blank & $35.4 \pm 2.066^{*}$ & $23.1 \pm 1.331^{*}$ \\
EPC & $24.5 \pm 4.301 \dagger$ & $17.3 \pm 2.908 \dagger$ \\
HIF-1-EPC & $15.4 \pm 1.897 \dagger, \dagger$ & $10.3 \pm 1.515 \dagger, \dagger$ \\
Control-EPC & $26.5 \pm 3.136 \dagger$ & $18.0 \pm 2.817 \dagger$ \\
Medium & $35.9 \pm 2.132^{*}$ & $23.4 \pm 1.389^{*}$ \\
\hline
\end{tabular}

Number in each group is $\mathrm{n}=10$. F-test: both $P<.05$. SPAP, Systolic pulmonary arterial pressure; $M P A P$, mean pulmonary arterial pressure; $E P C$, endothelial progenitor cell; $H I F$, hypoxia inducible factor. Tukey's test: Compared with the sham group. $* P<.05$; compared with the blank group. $\dagger P<.05$; compared with the EPC group. $\ddagger P<.05$. have congenital heart disease. In addition, we have successfully transfected the hHIF- $1 \alpha$ gene into EPCs, which overexpressed hHIF- $1 \alpha$ as a result. After transplantation of hHIF- $1 \alpha$-transfected EPCs into PAH rabbit models, systolic pulmonary arterial pressure, mean pulmonary arterial pressure, and the right ventricle hypertrophy index were significantly decreased. In addition, wall thickness and wall area of the small pulmonary arteries and muscular arteries, which reflect vascular remodeling, were significantly decreased. Compared with EPC treatment alone, these effects were more obvious with the use of combined HIF$1 \alpha$ and EPC therapy. Through immunohistochemical examination of antifactor VIII, we found that microvessel density was greater after transplantation of hHIF- $1 \alpha$-transfected EPCs. This finding indicates that angiogenesis played a key role in the combined HIF- $1 \alpha$ and EPC therapy.

Many previous studies have examined the treatment of PAH, including the use of bone marrow cell 

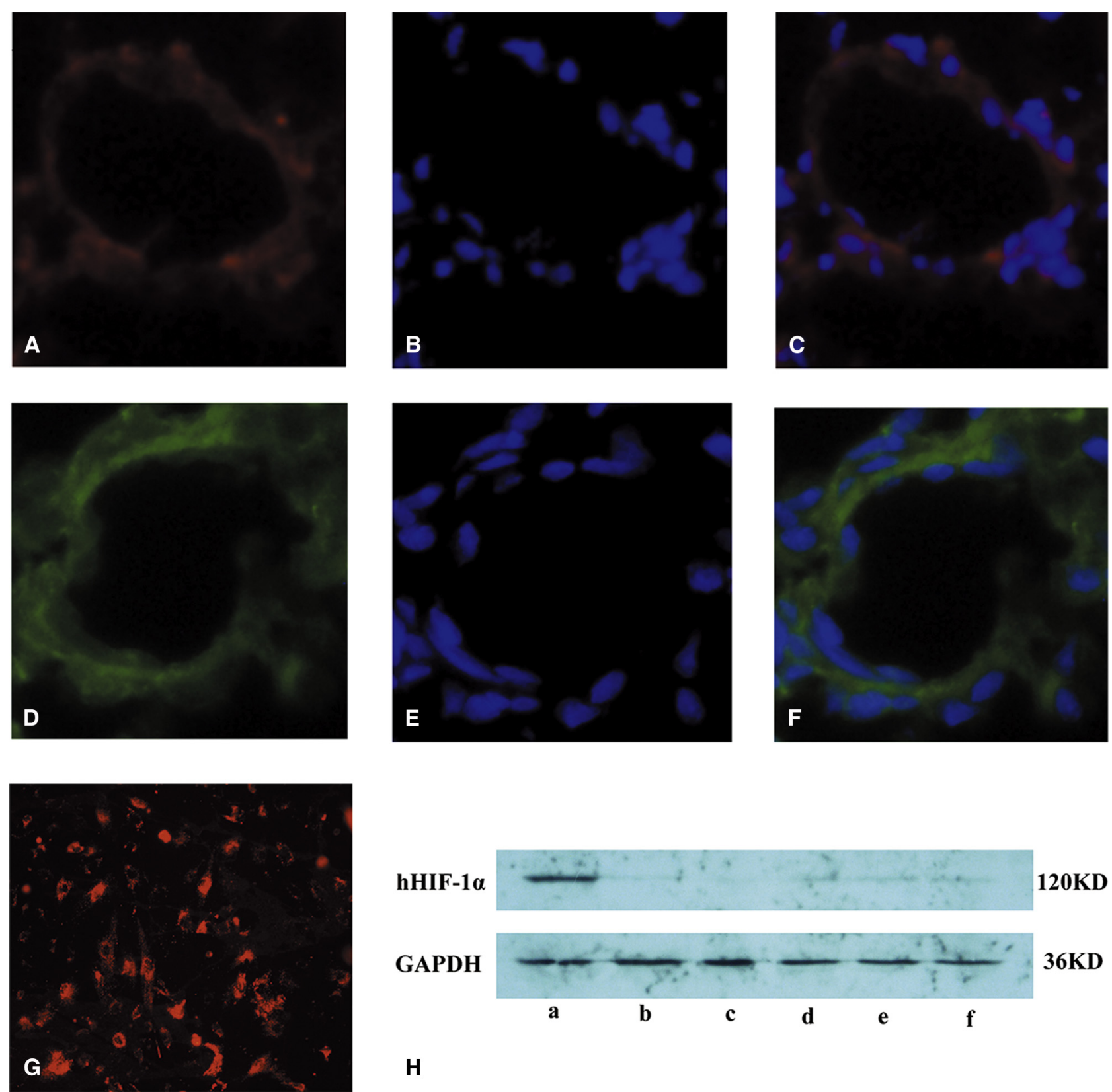

$120 K D$

FIGURE 5. Location of the hHIF- $1 \alpha$-transfected EPCs, and expression of hHIF- $1 \alpha$ in the lung. A, CM-Dil-labeled EPCs formed vascular structure. B, Nuclei of all the cells in the lung slice were stained purple by DAPI (4',6-diamidino-2-phenylindole). C, The vascular structure and nuclei (merged picture of parts A and B). D, hHIF- $1 \alpha$-transfected EPCs formed a vascular structure. E, Nuclei of all the cells in the lung slice were stained purple by DAPI. F, The vascular structure and nuclei (merged picture of parts D and E). G, EPCs labeled with CM-DiL. H, Expression of hHIF-1 $\alpha$ in the lung tissues ([a] the hHIF-1EPC group; $[b]$ the sham group; $[c]$ the blank group; $[d]$ the EPC group; $[e]$ the control-EPC group; $[f]$ the medium group.). $h H I F-1 \alpha$, Human hypoxia inducible factor-1 $\alpha$; GAPDH, glyceraldehyde 3-phosphate dehydrogenase.

infusion-attenuated vascular remodeling in a murine $\mathrm{PAH}$ model. $^{32}$ A novel agonist of the adenosine A2A receptor (LASSBio-1359) provided benefits in the treatment of $\mathrm{PAH},{ }^{33}$ and estradiol ameliorated monocrotaline-induced PAH. ${ }^{36}$ However, most PAH models have been established using monocrotaline; treatment of the hyperkinetic PAH model, which represents the aberrant hemodynamic state of congenital heart disease, has rarely been reported.
In our study, we tried to build a hyperkinetic PAH model using common carotid artery and jugular vein anastomosis in rabbits. Systolic pulmonary arterial pressure, mean pulmonary arterial pressure, right ventricle hypertrophy index, wall thickness, and wall area of the small pulmonary arteries and muscular arteries were significantly increased in our model system. Our data demonstrated that our hyperkinetic PAH model was successful. 

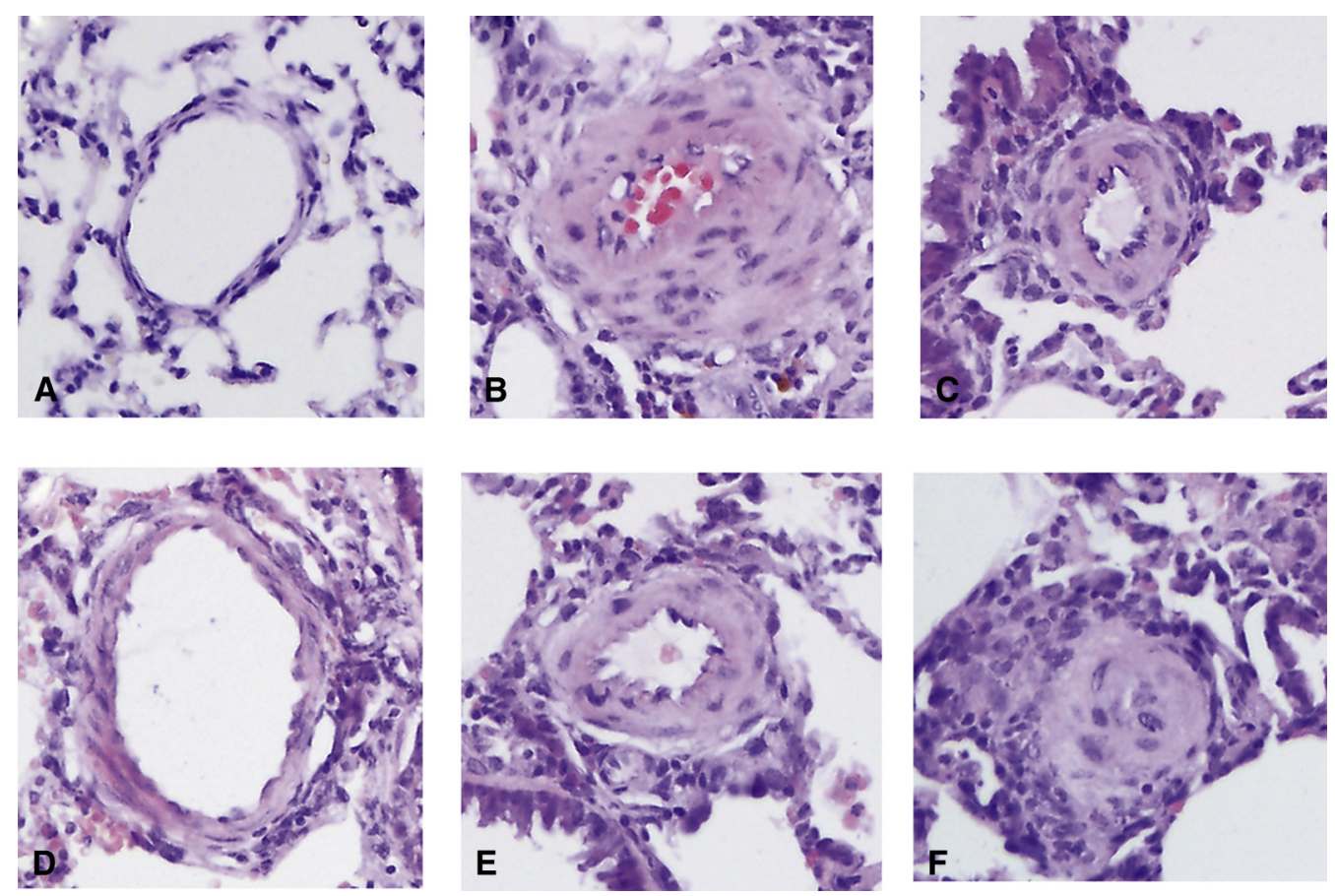

FIGURE 6. Combined therapy with both hHIF-1 $\alpha$ and EPCs reduced vascular remodeling: (A) the sham group; (B) the blank group; (C) the EPC group; (D) the hHIF-1-EPC group; (E) the control-EPC group; (F) the medium group.

The EPCs originate from bone marrow and have the ability to differentiate into multiple cell lines. In ischemic tissues, EPCs have a structural role and differentiate into mature endothelial cells that secrete angiogenic factors. As a result, homogeneous EPC transplantation was used to attenuate ischemic disease, including PAH. ${ }^{13,14}$ In the present study, EPCs in the EPC group were labeled with CM-DiL, and fluorescent microscopy was used to determine the location of the EPCs in the lung. We found that engrafted EPCs in the lung were almost always located in the surrounding capillary vessels and alveolar wall, 2 weeks after transplantation. Finally, compared with the blank group, systolic pulmonary arterial pressure, mean pulmonary arterial pressure, right ventricle hypertrophy index, wall thickness, and wall area of the small pulmonary arteries and muscular arteries decreased significantly in the EPC group. This observation was consistent with previous studies.
In our previous experiments, we discovered that recombinant HGF transfection alleviated hyperkinetic PAH in rabbit models. ${ }^{16} \mathrm{HGF}$ is a potent angiogenic gene that promotes angiogenesis and increases capillary density and blood perfusion. This increase in capillary density decreases vascular resistance when blood flow is increased. However, angiogenic growth factors such as VEGF and HGF have potential side effects, including vascular permeability, interstitial edema, and inflammation.

Compared with HGF, HIF-1 has many advantages. First, it increases the size of the vascular bed by signaling the existence of hypoxia, but it has no side effects. Second, HIF-1 is controllable. When PAH occurs, lung tissues are in ischemia and an anoxic state. Overexpression of both HIF-1 and HGF promotes angiogenesis, and PAH is attenuated because of increasing vascular density and blood perfusion. However, when lung tissues are in their normal state,

TABLE 2. The wall thickness and wall area of the small pulmonary arteries and muscular arteries

\begin{tabular}{|c|c|c|c|c|c|c|}
\hline \multirow[b]{2}{*}{ Group } & \multicolumn{3}{|c|}{ Small artery $(<\mathbf{5 0} \mu \mathbf{m})$} & \multicolumn{3}{|c|}{ Muscular artery $(51 \mu \mathrm{m}-200 \mu \mathrm{m})$} \\
\hline & External diameter $(\mu \mathbf{m})$ & WT $(\%)$ & WA $(\%)$ & External diameter $(\mu \mathrm{m})$ & WT $(\%)$ & WA $(\%)$ \\
\hline Sham & $35.04 \pm 9.14$ & $37.98 \pm 5.14$ & $61.30 \pm 6.25$ & $77.59 \pm 20.88$ & $38.69 \pm 6.24$ & $62.06 \pm 7.05$ \\
\hline Blank & $32.61 \pm 10.17$ & $62.88 \pm 6.45^{*}$ & $85.85 \pm 5.34^{*}$ & $96.38 \pm 42.87$ & $64.23 \pm 5.52^{*}$ & $86.93 \pm 4.15^{*}$ \\
\hline EPC & $33.09 \pm 10.76$ & $43.98 \pm 2.63 \dagger$ & $68.55 \pm 2.93 \dagger$ & $90.53 \pm 26.87$ & $43.95 \pm 6.15 \dagger$ & $68.24 \pm 6.33 \dagger$ \\
\hline HIF-1-EPC & $34.05 \pm 10.29$ & $38.44 \pm 3.73 \dagger, \dagger$ & $61.98 \pm 4.72 \dagger, \ddagger$ & $89.51 \pm 29.71$ & $38.81 \pm 5.15 \dagger, \ddagger$ & $62.31 \pm 6.30 \dagger$ \\
\hline Control-EPC & $35.21 \pm 8.28$ & $43.68 \pm 2.34 \dagger$ & $68.23 \pm 2.65 \dagger$ & $88.61 \pm 28.27$ & $45.01 \pm 6.70 \dagger$ & $69.36 \pm 6.67 \dagger$ \\
\hline Medium & $33.63 \pm 8.29$ & $63.39 \pm 5.40^{*}$ & $86.33 \pm 4.36^{*}$ & $94.09 \pm 38.47$ & $61.41 \pm 5.72^{*}$ & $84.81 \pm 4.43^{*}$ \\
\hline
\end{tabular}

Number in each group is $\mathrm{n}=10$. F-test: All $P<.05$. WT, Wall thickness; WA, wall area; $E P C$, endothelial progenitor cell; $H I F$, hypoxia inducible factor. Tukey's test: Compared

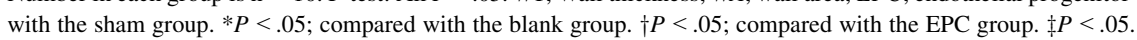



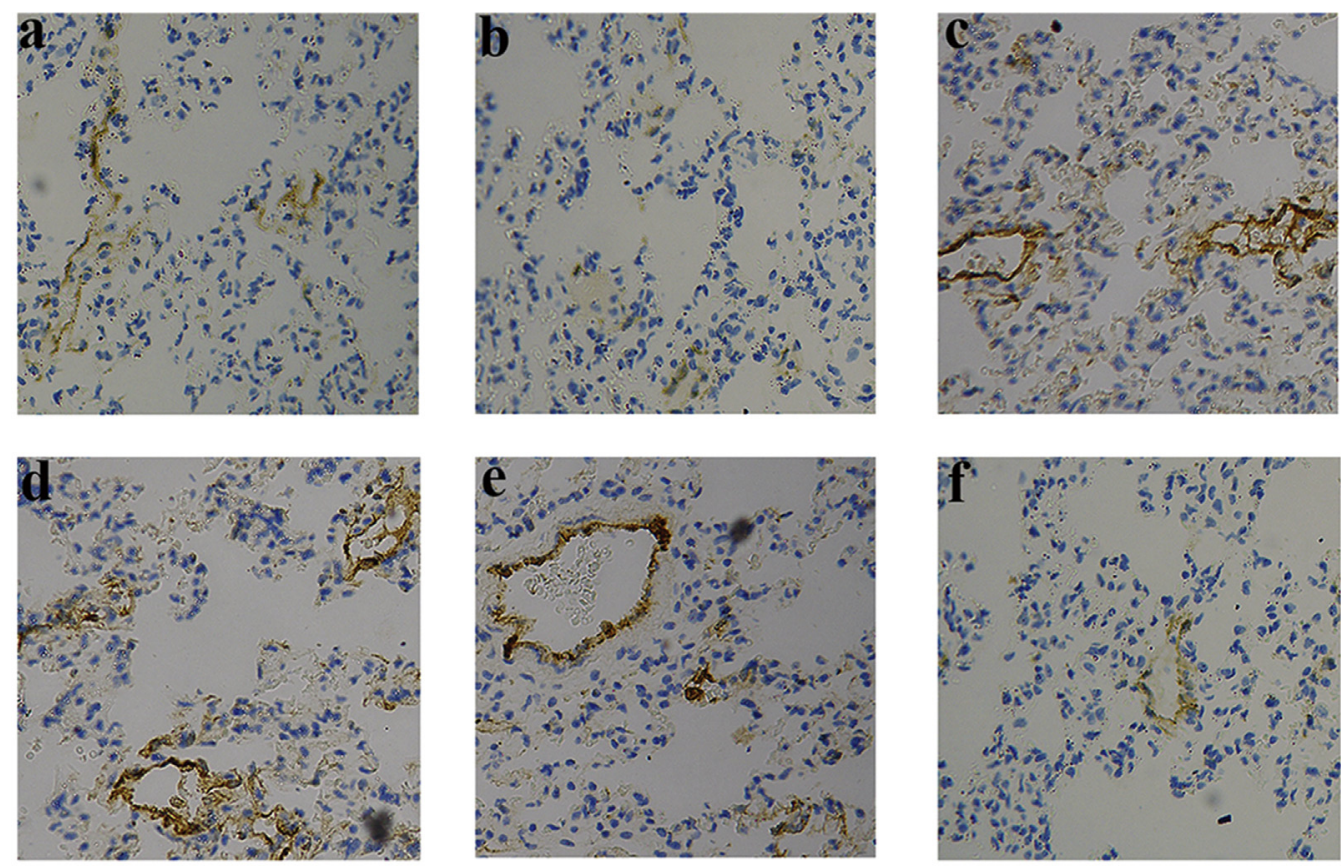

A
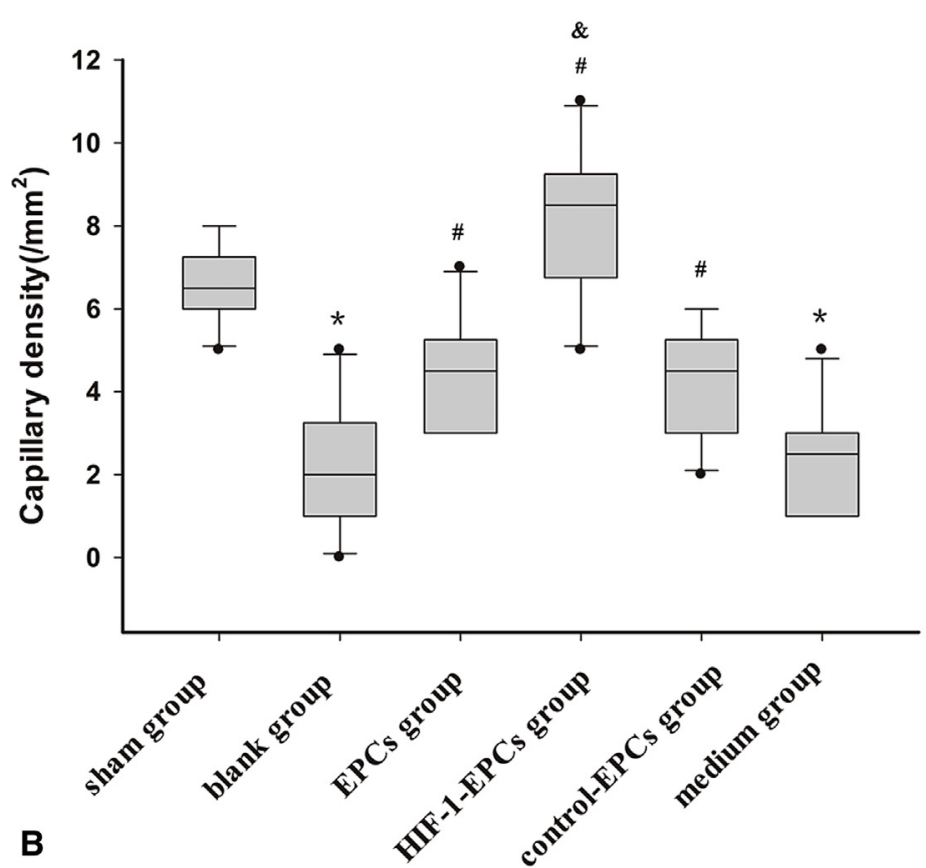

FIGURE 7. Assessment of capillary density after treatment. A, Immunohistochemistry staining of antifactor VIII ([a] the sham group; [b] the blank group; [c] the EPC group; [d] the hHIF-1-EPC group; [e] the control-EPC group; [f] the medium group]). B, Semiquantitative analysis of capillary density (compared with the sham group, $* P<.05$; compared with the blank group, $\# P<.05$; compared with the EPC group or control-EPC group, \&P<.05.) The median (horizontal line inside box) is shown, as well as a box showing the interquartile ranges (25th and 75 th percentiles); individual outlier points beyond the 10th and 90th percentiles are indicated. EPC, Endothelial progenitor cell; HIF, hypoxia inducible factor.

HIF-1 is dehydrated and angiogenesis is terminated. HGF still promotes angiogenesis, and vascular density increases continuously.

Third, HGF is a potent mitogen that has the ability to promote angiogenesis. HIF-1 is a nuclear transcriptional factor that regulates the transcription of downstream genes that mediate cellular and tissue homeostatic responses to altered oxygenation; therefore, HIF-1 gene therapy is more efficient than HGF gene therapy. Some studies ${ }^{37}$ have shown that HIF-1 could regulate the expression of its downstream genes, which guide EPC homing and promote neovascularization. In addition, HIF-1-EPC gene transfer could 
augment impaired neovascularization in experimentally induced mouse hind-limb ischemia in vivo. In our study, after the HIF-1-EPC gene was transferred, the hemodynamic changes and vascular remodeling of PAH were attenuated. In addition, the combination of HIF-1 and EPC therapy was more effective than EPC therapy alone.

To explore the mechanism of attenuated PAH in our study, we evaluated capillary density by examining the immunohistochemical expression of antifactor VIII. Compared with the blank group, all of the treatment groups had a significantly higher capillary density. The hHIF-1-EPCs group had a higher capillary density than the EPC group and the control-EPC group. The former demonstrated that transplanted EPCs migrate to the lung tissues and differentiate into mature endothelial cells. HIF-1 regulated and promoted neovascularization of the EPCs. In addition, we found that the wall thickness and wall area of the small pulmonary arteries and muscular arteries were significantly decreased after treatment.

We speculated that the mechanism of reversing vascular remodeling was associated with the transcription of downstream genes regulated by HIF-1. Some studies ${ }^{38-41}$ have shown that downstream genes related to vascular tone and remodeling include VEGF, $\alpha 1 \beta$-adrenergic receptor, adrenomedullin, endothelin-1, heme oxygenase-1, nitric oxide synthase, matrix metalloproteinase protein, angiotensin1 receptor, and platelet-derived growth factor- $\beta$. The question of whether 1 vascular factor alone, or the interaction of several vascular factors, results in the reversal of vascular remodeling after transplantation of hHIF-1-EPCs deserves further study.

In summary, a hyperkinetic PAH model was successfully established, using the common carotid artery and jugular vein anastomosis technique in rabbits. Transplantation of EPCs attenuated this shunt flow-induced PAH, and transfection of hHIF-1 promoted the effect of EPCs in vivo. The main mechanism of this effect was that angiogenesis gave rise to increasing vascular density and blood perfusion until the normal pulmonary arterial pressure was reached. At present, no effective therapeutic options are available for PAH treatment, despite its poor prognosis. Our study has important implications for hyperkinetic PAH therapy and provides further evidence to support future investigation of regenerative cell-based gene strategies for the treatment of patients who have severe PAH and congenital heart disease.

\section{Conflict of Interest Statement}

Authors have nothing to disclose with regard to commercial support.

\section{References}

1. Pietra G, Edwards W, Kay J, Rich S, Kernis J, Schloo B, et al. Histopathology of primary pulmonary hypertension. A qualitative and quantitative study of pulmonary blood vessels from 58 patients in the National Heart, Lung, and Blood Institute, primary pulmonary hypertension registry. Circulation. 1989;80:1198-206.
2. Talwar S, Keshri VK, Choudhary SK, Gupta SK, Ramakrishnan S, Saxena A, et al. Unidirectional valved patch closure of ventricular septal defects with severe pulmonary arterial hypertension: hemodynamic outcomes. J Thorac Cardiovasc Surg. 2014;148:2570-5.

3. Roos-Hesselink J, Meijboom F, Spitaels S, Van Domburg R, van Rijen E, Utens E, et al. Outcome of patients after surgical closure of ventricular septal defect at young age: longitudinal follow-up of 22-34 years. Eur Heart J. 2004; 25:1057-62.

4. Tuder RM, Cool CD, Yeager M, Taraseviciene-Stewart L, Bull TM, Voelkel NF. The pathobiology of pulmonary hypertension: endothelium. Clin Chest Med. 2001;22:405-18.

5. Voelkel NF, Quaife RA, Leinwand LA, Barst RJ, McGoon MD, Meldrum DR, et al. Right ventricular function and failure report of a National Heart, Lung, and Blood Institute working group on cellular and molecular mechanisms of right heart failure. Circulation. 2006;114:1883-91.

6. Humbert M, Sitbon O, Simonneau G. Treatment of pulmonary arterial hypertension. N Engl J Med. 2004;351:1425-36.

7. Michelakis ED, Wilkins MR, Rabinovitch M. Emerging concepts and translational priorities in pulmonary arterial hypertension. Circulation. 2008;118:1486-95.

8. Galie N, Manes A, Palazzini M, Negro L, Marinelli A, Gambetti S, et al. Management of pulmonary arterial hypertension associated with congenital systemic-to-pulmonary shunts and Eisenmenger's syndrome. Drugs. 2008;68: 1049-66.

9. Cristofaro B, Stone OA, Caporali A, Dawbarn D, Ieronimakis N, Reyes M, et al. Neurotrophin-3 is a novel angiogenic factor capable of therapeutic neovascularization in a mouse model of limb ischemia. Arterioscler Thromb Vasc Biol. 2010;30:1143-50.

10. Oostendorp M, Douma K, Wagenaar A, Slenter JM, Hackeng TM, van Zandvoort MA, et al. Molecular magnetic resonance imaging of myocardial angiogenesis after acute myocardial infarction. Circulation. 2010;121:775-83.

11. Jiang L, Song XH, Liu P, Zeng CL, Huang ZS, Zhu LJ, et al. Platelet-mediated mesenchymal stem cells homing to the lung reduces monocrotaline-induced rat pulmonary hypertension. Cell Transplant. 2012;21:1463-75.

12. Liu K, Liu R, Cao G, Sun H, Wang X, Wu S. Adipose-derived stromal cell autologous transplantation ameliorates pulmonary arterial hypertension induced by shunt flow in rat models. Stem Cells Develop. 2010;20:1001-10.

13. Toshner M, Morrell NW. Endothelial progenitor cells in pulmonary hypertension-dawn of cell-based therapy? Int J Clin Pract Suppl. 2010;165:7-12.

14. Yip HK, Chang LT, Sun CK, Sheu JJ, Chiang CH, Youssef AA, et al. Autologous transplantation of bone marrow-derived endothelial progenitor cells attenuates monocrotaline-induced pulmonary arterial hypertension in rats. Crit Care Med. 2008;36:873-80.

15. Yao EH, Fukuda N, Matsumoto T, Katakawa M, Yamamoto C, Han Y, et al. Effects of the antioxidative $\beta$-blocker celiprolol on endothelial progenitor cells in hypertensive rats. Am J Hyperten. 2008;21:1062-8.

16. Wang W, Liu K, Zhang F, Cao G, Zhang Y, Liu R, et al. Recombinant human hepatocyte growth factor transfection alleviates hyperkinetic pulmonary artery hypertension in rabbit models. J Thorac Cardiovasc Surg. 2013;146:198-205.

17. Zhang F, Wu S, Lu X, Wang M, Liu M. Gene transfer of endothelial nitric oxide synthase attenuates flow-induced pulmonary hypertension in rabbits. Ann Thorac Surg. 2008;85:581-5.

18. Farkas L, Farkas D, Ask K, Moller A, Gauldie J, Margetts P, et al. Vegf ameliorates pulmonary hypertension through inhibition of endothelial apoptosis in experimental lung fibrosis in rats. J Clin Invest. 2009;119:1298-311.

19. Gubrij IB, Martin SR, Pangle AK, Kurten RC, Johnson LG. Attenuation of monocrotaline-induced pulmonary hypertension by luminal aav serotype 9 gene transfer of prostacyclin synthase. Hum Gene Ther. 2014;25:498-505.

20. Takemiya K, Kai H, Yasukawa H, Tahara N, Kato S, Imaizumi T. Mesenchymal stem cell-based prostacyclin synthase gene therapy for pulmonary hypertension rats. Basic Res Cardiol. 2010;105:409-17.

21. Yamazato Y, Ferreira AJ, Hong KH, Sriramula S, Francis J, Yamazato M, et al Prevention of pulmonary hypertension by angiotensin-converting enzyme 2 gene transfer. Hypertension. 2009;54:365-71.

22. Su H, Arakawa-Hoyt J, Kan YW. Adeno-associated viral vector-mediated hypoxia response element-regulated gene expression in mouse ischemic heart model. Proc Natl Acad Sci. 2002:99:9480-5.

23. Yamakawa M, Liu LX, Date T, Belanger AJ, Vincent KA, Akita GY, et al. Hyp oxia-inducible factor- 1 mediates activation of cultured vascular endothelial cells by inducing multiple angiogenic factors. Circ Res. 2003;93:664-73.

24. Khan T, Sellke F, Laham R. Gene therapy progress and prospects: therapeutic angiogenesis for limb and myocardial ischemia. Gene Ther. 2003;10:285-91. 
25. Hoenig MR, Bianchi C, Rosenzweig A, Sellke FW. Decreased vascular repair and neovascularization with ageing: mechanisms and clinical relevance with an emphasis on hypoxia-inducible factor-1. Curr Mol Med. 2008;8:754-67.

26. Nagaya N, Kangawa K, Kanda M, Uematsu M, Horio T, Fukuyama N, et al. Hybrid cell-gene therapy for pulmonary hypertension based on phagocytosing action of endothelial progenitor cells. Circulation. 2003;108:889-95.

27. Iwaguro H, Yamaguchi JI, Kalka C, Murasawa S, Masuda H, Hayashi S-I, et al. Endothelial progenitor cell vascular endothelial growth factor gene transfer for vascular regeneration. Circulation. 2002;105:732-8.

28. Zhao YD, Courtman DW, Deng Y, Kugathasan L, Zhang Q, Stewart DJ. Rescue of monocrotaline-induced pulmonary arterial hypertension using bone marrowderived endothelial-like progenitor cells: efficacy of combined cell and eNOS gene therapy in established disease. Circ Res. 2005;96:442-50.

29. Zhao Q, Liu Z, Wang Z, Yang C, Liu J, Lu J. Effect of prepro-calcitonin generelated peptide-expressing endothelial progenitor cells on pulmonary hypertension. Ann Thorac Surg. 2007;84:544-52.

30. Liu C, Yan Z, Fang C, Cao G, Wang B, Li S, et al. Establishment and comparison of two reliable hyperkinetic pulmonary hypertension models in rabbits. J Thorac Cardiovasc Surg. 2014;148:2353-9.

31. Griese DP, Achatz S, Batzlsperger CA, Strauch UG, Grumbeck B, Weil J, et al. Vascular gene delivery of anticoagulants by transplantation of retrovirallytransduced endothelial progenitor cells. Cardiovasc Res. 2003;58:469-77.

32. Aliotta JM, Keaney PJ, Warburton RR, DelTatto M, Dooner MS, Passero MA, et al. Marrow cell infusion attenuates vascular remodeling in a murine model of monocrotaline-induced pulmonary hypertension. Stem Cells Develop. 2008; 18:773-81

33. Alencar AK, Pereira SL, Montagnoli TL, Maia RC, Kümmerle AE, Landgraf SS, et al. Beneficial effects of a novel agonist of the adenosine a2a receptor on monocrotaline-induced pulmonary hypertension in rats. Br J Pharmacol. 2013; 169:953-62.

34. George AL, Bangalore-Prakash P, Rajoria S, Suriano R, Shanmugam A, Mittelman A, et al. Endothelial progenitor cell biology in disease and tissue regeneration. J Hematol Oncol. 2011;4:24-31.

35. Liu L, Liu ZZ, Chen H, Zhang GJ, Kong YH, Kang XX. Oxidized low-density lipoprotein and $\beta$-glycerophosphate synergistically induce endothelial progenitor cell ossification. Acta Pharmacol Sinica. 2011;32:1491-7.

36. Yuan P, Wu WH, Gao L, Zheng ZQ, Liu D, Mei HY, et al. Oestradiol ameliorates monocrotaline pulmonary hypertension via no, prostacyclin and endothelin-1 pathways. Eur Respir J. 2013;41:1116-25.

37. Jiang M, Wang B, Wang C, He B, Fan H, Guo TB, et al. Angiogenesis by transplantation of hif-1 alpha modified epcs into ischemic limbs. J Cell Biochem. 2008;103:321-34.

38. Hanze J, Weissmann N, Grimminger F, Seeger W, Rose F. Cellular and molecular mechanisms of hypoxia-inducible factor driven vascular remodeling. Thromb Haemost. 2007:97:774.

39. Semenza GL. Hif-1: mediator of physiological and pathophysiological responses to hypoxia. J Appl Physiol. 2000;88:1474-80.

40. Hu J, Discher DJ, Bishopric NH, Webster KA. Hypoxia regulates expression of the endothelin-1 gene through a proximal hypoxia-inducible factor-1 binding site on the antisense strand. Biochem Biophys Res Commun. 1998;245:894-9.

41. Lim CS, Kiriakidis S, Sandison A, Paleolog EM, Davies AH. Hypoxia-inducible factor pathway and diseases of the vascular wall. J Vasc Surg. 2013;58:219-30.

Key Words: Congenital heart disease, pulmonary arterial hypertension, HIF-1 $\alpha$, endothelial progenitor cells, rabbits

\section{EDITORIAL COMMENTARY}

\section{Gene-enhanced cell therapy for pulmonary arterial hypertension: Knocking at the clinical door?}

Peter Donndorf, MD, and Alexander Kaminski, MD, PhD

See related article on pages 621-32.

Pulmonary arterial hypertension (PAH) is a progressive disease, characterized by increased resistance in the pulmonary circulation as a result of obstructive remodeling of the pulmonary arterioles. Hyperkinetic PAH represents an old

From the Department of Cardiac Surgery, University Heart Center Rostock, Rostock, Germany.

Disclosures: Authors have nothing to disclose with regard to commercial support. Received for publication June 16, 2015; accepted for publication June 17, 2015; available ahead of print July 18, 2015

Address for reprints: Peter Donndorf, MD, Department of Cardiac Surgery, University Heart Center Rostock, Schillingallee 35, 18057 Rostock, Germany (E-mail: peter.donndorf@med.uni-rostock.de).

J Thorac Cardiovasc Surg 2015;150:632-3

$0022-5223 / \$ 36.00$

Copyright (C) 2015 by The American Association for Thoracic Surgery

http://dx.doi.org/10.1016/j.jtcvs.2015.06.039 yet fundamental problem in congenital heart disease, contributing significantly to morbidity and mortality even before the complete develop-

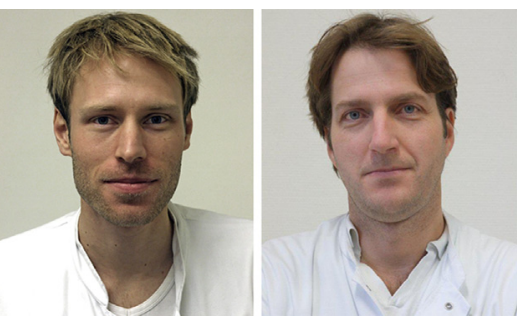
ment of Eisenmenger syndrome.

The classic surgical concept for palliation of hyperkinetic $\mathrm{PAH}$, namely pulmonary artery banding, was already described by Muller and Danimann ${ }^{1}$ in 1951. More recent pharmacologic concepts in both adult and pediatric patients include such treatments as nitric oxide inhalation and the application of prostacyclin analogs or endothelin antagonists. Although there has been success in improving symptoms and the quality of life for patients with $\mathrm{PAH}$, the long-term outcome of these concepts remains to be proved, especially with respect to survival and 